\title{
Cardiomyopathy Induced by Artificial Heart Stimulation
}

\author{
Cardiomiopatia Induzida por Estimulação Cardíaca Artificial
}

\author{
Silas dos Santos Galvão Filho ${ }^{1, *}$
}

With the advent of cardiac pacemakers more than 60 years ago, the era of artificial cardiac pacing began, which changed the natural history of symptomatic bradycardias, significantly increasing the survival especially of patients with complete atrioventricular block. Initially, the pacemakers were ventricular single chamber (VVI), bringing some limitations in patients with bradycardia consequent to sinus dysfunction, which mostly presented ventriculoatrial retrograde conduction, determining atrioventricular dyssynchrony with damage to cardiac function and consequent symptoms, which was called pacemaker syndrome ${ }^{1}$. In the early 1980s, the incorporation of one more electro in the atrium and the development of dual chamber pacemakers (DDD), also called "physiological pacemakers", recovered the atrioventricular synchronism and solved this problem. The success of dual-chamber pacemakers led to the idea that they could further increase the survival of their carriers compared to VVI. However, although DDD pacemakers show benefits in tolerance to effort and improvement in quality of life, no significant increase in survival was evidenced in this comparison.

In the first years of the second millennium, concomitant to the appearance of cardiac resynchronization therapy (CRT) and the concepts of dyssynchronization, it was observed that patients with double chamber devices that presented effective ventricular pacing in more than $40 \%$ of the heartbeat presented some problems, such as: appearance or worsening of heart failure, development of atrial fibrillation and even increased mortality ${ }^{2-4}$ when compared to those who did not present RV stimulation, being that the worse and the greater the percentage of ventricular stimulation. These problems were attributed to ventricular dyssynchrony caused by RV stimulation and led to the development of programmable algorithms of minimal ventricular pacing in artificial cardiac pacing devices in order to avoid unnecessary ventricular stimulations in patients who had preserved atrioventricular and interventricular conduction.

Already in cases of atrioventricular blocks, where RV stimulation is absolutely necessary, new optional stimulation sites to the classical RV tip stimulation have been sought. In this sense, several ventricular pacing sites were attempted: $\mathrm{RV}$ outflow tract, mid-septal, inferoseptal region, without, however, showing significant differences when compared to classical RV tip stimulation ${ }^{5,6}$.

In recent years, the development of special sheaths and electrodes for stimulation of the His bundle enabled this type of cardiac stimulation that preserves the interventricular conduction through the normal conduction system, consequently avoiding ventricular dyssynchrony induced by RV stimulation ${ }^{7,8}$. This modality of stimulation, however, has its indication in cases that present intraventricular conduction preserved through the normal conduction system, because in cases where there are intraventricular conduction disorders such as the left bundle branch block (LBBB), the His bundle stimulation does not bring benefits, since it determines the persistence of conduction disorder and, consequently, dyssynchrony. More recently, using the same system developed for His pacing, the muscle region of the interventricular septum was stimulated, immediately below the fibrotic portion where the trunk of the His bundle

1.Centro Avançado de Ritmologia e Eletrofisiologia - São Paulo (SP), Brazil.

Received: Mar. 10, 2020 | Accepted: Mar. 20, 2020

*Correspondence author: sdsantos@uol.com.br

ORCID: Galvão Filho SS (iD https://orcid.org/0000-0002-5152-2648 
is located, penetrating the interventricular septum and stimulating the initial portions of the His bundle branches, correcting in many cases conduction disorders such as LBBB. This promising modality of artificial cardiac pacing has been placed as an option of unisite pacing to CRT with biventricular pacing, although it still needs more knowledge of its long-term results.

Our idea that ventricular dyssynchrony could induce dilated myocardiopathy started with a study we presented in 1997 at the Congresso Brasileiro de Arritmias Cardiacas (Brazilian Congress of Cardiac Arrhythmias) ${ }^{10}$, where a study was presented with 12 patients with idiopathic dilated cardiomyopathy who had ventricular dyssynchrony (LBBB), reduced left ventricle ejection fraction (LVEF) $(<35 \%)$, and CHF refractory to drug therapy, which, after CRT, normalized the cardiac systolic function with LVEF normalization. In three of these patients there was normalization of all echocardiographic parameters with the examination showing a structurally normal heart. We attributed the appearance of dilated cardiomyopathy considered idiopathic to the dyssynchrony determined by LBBB, which we named "dyssyncronyomyopathy".

Conventional RV pacing determines the electrocardiographic pattern of LBBB, with QRS width frequently greater than $150 \mathrm{~ms}$ and changes in myocardial ventricular contractility (dyssynchrony) similar to LBBB, with damage to the cardiac systolic function ${ }^{11}$. In some (but not all) patients, these alterations may be responsible for the appearance and/or worsening of heart failure and even structural alterations of the heart, and may therefore be responsible for the development of "dyssyncronyomyopathy". These patients benefit greatly from the CRT upgrade call, with the implantation of another electrode for LV stimulation.

Gage et al. ${ }^{12}$ published a study in which they compared the clinical and echocardiographic response to CRT of patients with or without previous conventional cardiac pacing (PCCP), showing a similar positive clinical response between both groups and a better response of patients with PCCP regarding ventricular function evaluated by eco. In addition, a trend of lower mortality of patients with PCCP was demonstrated when compared to those with no PCCP. The authors concluded that patients submitted to CRT upgrade of pacemakers present a similar, if not better, response than CRT in patients without PCCP.

Several studies such as that of Martineli et al. ${ }^{13}$ showed better results of CRT implantation when compared to the conventional pacemaker in patients with indication for ventricular pacing and reduced ventricular systolic function. Recently, a systematic review ${ }^{14}$ was published involving 679 patients from eight studies that evaluated the impact of what they called physiological cardiac pacing (PCP) (CRT or His/ParaHis) versus conventional cardiac pacing in patients with indication for cardiac pacemakers and moderately impaired ventricular systolic function (> 35\%), and significant superiority of PCP in relation to echocardiographic parameters (LVEF, LV end diastolic volume, LV end systolic volume) was demonstrated.

In the European Society of Cardiology (ESC) for the management of CHF $2016^{15}$, the CRT is class 1 in patients with indication for cardiac pacing who require $\mathrm{RV}$ pacing and have $\mathrm{EF}<40 \%$, to the detriment of conventional pacemakers. In these guidelines, the CRT upgrade for pacemaker is indicated for patients with systolic dysfunction (LVEF < 40\%) who present worsening of $\mathrm{CHF}$ after device implantation with $\mathrm{RV}$ pacing in more than $40 \%$ of the heartbeats.

Although it may cause damage to the cardiac systolic function in some patients, it may even be responsible for the appearance/aggregation of dilated cardiomyopathies called "dyssyncronyomyopathies", conventional unisite pacing RV remains routinely used. The good evolution of the majority of conventional pacemaker patients, the greater complexity of biventricular pacing procedures and even the much higher costs of CRT devices limit the more frequent use of this type of cardiac pacing in patients with indication for pacemakers that require ventricular pacing. Transeptal stimulation of the initial portions of His bundle branches can be an excellent option for unisite stimulation from RV to CRT with biventricular stimulation.

Having knowledge of the possible damage caused by unisite RV stimulation of conventional pacemakers, the carriers of these devices should be evaluated in relation to the structural and functional part of the heart, through imaging methods such as echocardiography, at least annually and, if they show relevant and/or progressive changes, upgrade for CRT should always be considered. 


\section{REFERENCES}

1. Mitsue T, Hori M, Suma K et al. The "pacemaker syndrome". In: JacobJE (ed). Proceedings of the Right Annual International Conference on Medical and Biological Engineering. Chicago: Association for the Advancement of Medical Instrumentation; 1969. 29-33 p.

2. The DAVID Trial Investigators. Dual-chamber pacing or ventricular backup pacing in patients with and implantable defibrillator: The dual-chamber and WI implantable defibrillator (DAVID) trial. JAMA. 2002;288(24):3115-23. https://doi.org/10.1001/jama.288.24.3115

3. Sweeney MO, Helkamp AS, Ellenboge KA, Greenspon AJ, Freedman RA, Lee KL et al. Mode selection trial. Adverse effect of ventricular pacing on heart failure and atrial fibrillation among patients with normal baseline QRS duration in a clinical trial of pacemaker therapy for sinus node dysfunction. Circulation. 2003;107(23):2932-7. https://doi.org/10.1161/01.CIR.0000072769.17295.B1

4. Nielsen JC, Kristensen L, Andersen HR, Mortensen PT, Pedersen OL, Pedersen AK. A randomized comparation of atrial and dualchamber pacing in 17 consecutive patients with sick sinus syndrome: echocardiographic and clinic outcome. J Am Coll Cardiol. 2003;42(4):614-23. https://doi.org/10.1016/S0735-1097(03)00757-5

5. Zografos TA, Siontis KC, Jastrzebski M, Kutyifa V, Klein HU, Zareba W, et al. Apical vs. non-apical right ventricular pacing in cardiac resynchronization therapy: a meta-analysis. EP Eur. 2015;17(8):1259-66. https://doi.org/10.1093/europace/euv048

6. Shimony A, Eisemberg MJ, Filion KB, Amit G. Beneficial effects of right ventricular non-apical vs. apical pacing: a systematic review and meta-analysis of randomized-controlled trials. EP Eur. 2012;14(1):81-91. https://doi.org/10.1093/europace/eur240

7. Vijayaraman P, Chung MK, Dandamudi G, Upadhyay GA, Krishnan K, Grossley G, et al. ACC's Electrophysiology Council. His Bundle Pacing. J Am Coll Cardiol. 2018;72(8):927-47.

8. Ali N, Kreene D, Arnold A, Shun-Shin M, Whinnett ZI, Sohaib A. His bundle pacing: a new frontier in the treatment of heart failure. Arrhythm Electrophysiol Rev. 2018;7(2):103-10. https://doi.org/10.15420/aer.2018.6.2

9. Upadhyay GA, Cherian T, Shatz DY, Beazer AD, Aziz Z, Ozcan C, et al. Intracardiac delineation of septal conduction in left bundlebranch block patterns. Circulation. 2019;139(16):1876-88. https://doi.org/10.1161/CIRCULATIONAHA.118.038648

10. Sacramento ERS, Galvão Filho SS, Vasconcelos JTM, Leobino E, Fragata C, Barcelos C. Normalização da função sistólica ventricular na cardiomiopatia dilatada idiopática pós ressincronização cardíaca. Tratamento da "dissincroniomiopatia". Relampa. 2007;20(4):272.

11. Bank AJ, Schwarzman DS, Burns KV, Kaufman CL, Adler SW, Kelly AS, et al. Intramural dyssynchrony from acute right ventricular apical pacing in human subjects with normal left ventricular function. J Cardiovasc Trans Res. 2010;3:321-29. https://doi.org/10.1007/s12265-010-9176-8

12. Gage RM, Burns KV, Bank AJ. Echocardiographic and clinical response to cardiac resynchronization therapy in heart failure patients with and without previous right ventricular pacing. Eur J Heart Fail. 2014;16(11):1199-205. https://doi.org/10.1002/ejhf.143

13. Martinelli Filho M, Siqueira SF, Costa R, Greco OT, Moreira LF, D'Avila A, et al. Conventional versus biventricular pacing in heart failure and bradyarrhythmia: the COMBAT study. J Cardiac Fail. 2010;16(4):293-300. https://doi.org/10.1016/j.cardfail.2009.12.008

14. Slotwiner DJ, Rait MH, Munoz FD-C, Mulpuru SK, Nasser N, Peterson PN. Impact of physiologic pacing versus right ventricular pacing among patients with left ventricular ejection fraction greater than 35\%: a systematic review for the 2018 ACC/AHA/HRS guidelines on the evaluation and management of patients with bradycardia and cardiac conduction delay. A report of the American College of Cardiology/American Heart Association Task Force on Clinical Practice Guidelines and the Heart Rhythm Society. Circulation. 2019;140(8):e483-503. https://doi.org/10.1161/CIR.0000000000000722

15. Ponikowski P, Voors AA, Anker SD, Bueno H, Cleland JG, Coats AJ, et al. 2016 ESC Guidelines for the diagnosis and treatment of acute and chronic heart failure: The Task Force for the diagnosis and treatment of acute and chronic heart failure of the European Society of Cardiology (ESC). Developed with the especial contribution of the Heart Failure Association (HFA) of the ESC. Eur J Heart Fail. 2016;18(8):891-975. 